\title{
Correction to: Evaluation of recent drought conditions by standardized precipitation index and potential evapotranspiration over Indonesia
}

\author{
Y. Pramudya ${ }^{1} \cdot$ T. Onishi ${ }^{2} \cdot$ M. Senge ${ }^{3} \cdot$ K. Hiramatsu ${ }^{2} \cdot$ Prasetyo M. R. Nur $^{4}$
}

Published online: 23 May 2019

(C) The International Society of Paddy and Water Environment Engineering 2019

\section{Correction to: Paddy and Water Environment}

https://doi.org/10.1007/s10333-019-00728-z

In the original publication of this article, the co-author Komariah Komariah has been included incorrectly. Now the same name has been removed from the author group.

The original article has been corrected.

The original article has been corrected and can be found online at https://doi.org/10.1007/s10333-019-00728-z.

Y. Pramudya

pramudyayudhi@gmail.com

1 Graduate School of Applied Biological Sciences, Gifu University, 1-1 Yanagido, Gifu 501-1193, Japan

2 Faculty of Applied Biological Sciences, Gifu University, 1-1 Yanagido, Gifu 501-1193, Japan

3 United Graduate School of Agricultural Science, Gifu University, 1-1 Yanagido, Gifu 501-1193, Japan

4 Indonesia Agency for Meteorology Climatology and Geophysics, Jalan Angkasa I-2, Kemayoran, Jakarta 10720, Indonesia 